\title{
The effects of major genes on quantitatively varying characters in barley 2. The denso and daylength response loci
}

\author{
W. Powell, $\dagger$ \\ P. D. S. Caligari, $\dagger$ \\ W. T. B. Thomas $\dagger$ and \\ J. L. Jinks*
}

\author{
† S.C.R.I., Pentlandfield, Roslin, Midlothian EH25 \\ 9RF, U.K. \\ * Genetics Department, Univ. of Birmingham, \\ Birmingham, B15 2TT, U.K.
}

\begin{abstract}
The effects of the denso dwarfing gene and a locus determining daylength response on quantitative characters have been examined in random inbred lines. Since random inbred lines were produced from $F_{1}$ hybrids by doubled haploidy and single seed descent it was possible to quantify the contribution of each individual locus to the additive genetic variation $(D)$ for any given character. It was observed that the contribution of these loci to estimates of $D$ decreased following rounds of recombination which therefore demonstrated that in these cases the association between major genes and quantitative characters was due to linkage disequilibria. The implications of these findings to barley breeding programmes are discussed.
\end{abstract}

\section{INTRODUCTION}

The isolation of single genetic factors affecting quantitatively varying characters is of great interest to plant breeders. Such associations may be due to pleiotropic effects and/or linkage disequilibrium. For the plant breeder the distinction between pleiotropy and tight linkage may not always be important, but since major genes are frequently manipulated in breeding programmes it is essential to examine the effects of such genes on agronomic characters. By producing random inbred lines it has been shown that the GP ert locus can influence the expression of quantitative characters in spring barley, (Powell, Thomas, Caligari and Jinks, 1985). Investigations using lines developed in this way allow the advantages and disadvantages of a particular genetic locus to be assessed in terms of other agronomic characters. The GP ert locus appeared to be associated with reduced grain weight, height and caused a reduction in single plant yield. An alternative simply inherited source of short straw is the recessive denso dwarfing gene (Haahr and von Wettstein, 1975). This gene confers a prostrate growth habit and is present in the variety Universe. In this paper the analysis of random inbred lines is extended to include the denso dwarfing gene and a locus determining daylength response which is present in the variety Clipper (Thomson and Matthews, 1981). Furthermore by comparing the contribution of alleles at these loci to estimates of the additive genetic variance $(D)$ in $F_{1}$ derived doubled haploids and single seed descent lines it is possible to assess the relative contribution of pleiotropy and linkage disequilibrium to any associations that may be detected. This information will enable the barley breeder to adopt the most efficient strategy for the deployment of these major genes in breeding programmes.

\section{MATERIALS AND METHODS}

Twenty doubled haploids (produced by the Hordeum bulbosum technique) were produced from 
F1 hybrids of the following spring barley crosses: Universe $\times$ Mazurka (TT2)

Clipper $\times$ Ymer (TT5)

In addition single seed descent (SSD) lines were derived from $\mathrm{F}_{2}$ individuals and 40 such lines from each cross were used in the present experiment. Parents, doubled haploids (DH) and. SSD lines were grown in a replicated, randomised spaced plant experiment in 1983 at the Murrays Farm, East Lothian. Universe possesses the denso allele giving a prostrate growth habit while Mazurka has the nutans allele. This cross will therefore segregate for alleles at the denso locus. Clipper, an Australian variety, is responsive to long days ("early") when compared to European varieties and is adapted for growth in a restricted season such as a South Australian winter. Data from the $F_{2}$ generation and $F_{1}$ derived doubled haploids indicated that this daylength response is controlled by a single major gene. The TT5 cross will therefore segregate for alleles at this locus. It was thus possible to classify the inbreds from the TT2 cross into two sub-groups (the denso and nutans groups) and similarly the TT5 cross could be classified in to "early" and "late" groups. The method of sowing and details of scoring procedures may be found in Powell, Thomas, Caligari and Jinks (1985). The characters scored were: height $(\mathrm{Ht})$, thousand grain weight (TGW), yield of grain on the main stem (MSW), ear length (EL), number of fertile tillers (TN), number of grains per ear (GN), maturity (Mat), awn emergence (AE) and single plant yield (SPY).

\section{RESULTS}

The analysis of variance for the 9 variates scored on the Universe $\times$ Mazurka cross are presented in table 1 . There were significant differences between
DH lines for height, ear length and tiller number. The SSD lines displayed significant between line variation for height and maturity. In the case of the DH population there were significant differences between the two sub-populations (denso and nutans groups) for height, ear length and single plant yield indicating an association between this locus and these quantitatively varying characters. The means of the denso and nutans populations differed in the SSD population not only for height (as did the DH) but also for grain number and awn emergence.

Estimates of the total additive genetic variation (D) and that associated with the denso dwarfing gene (calculated using the method of Al-Banna, Jinks and Pooni, 1984) for the DH and SSD lines are given in table 2 . In the case of height, estimates

Table 2 Estimates of the total additive genetic variance $(D)$ and that associated with the denso locus for the DH lines and SSD lines

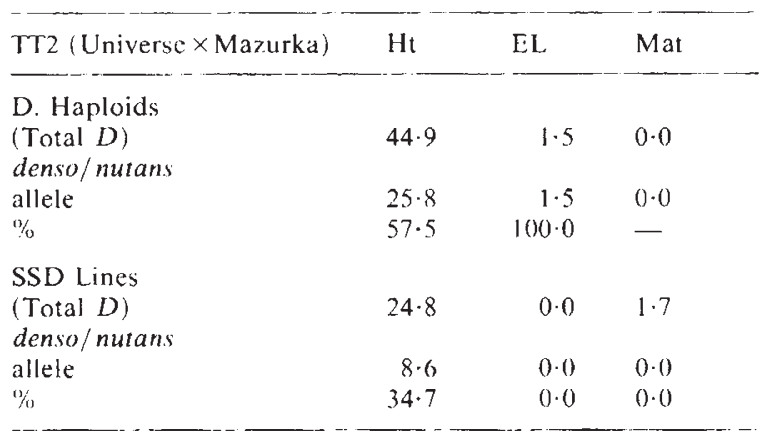

of $D$ associated with the denso locus decreased from 57.5 per cent in the DH lines to 34 per cent in the SSD lines. This corresponds to one round of gametogenesis in the $\mathrm{DH}$ generation and 3 rounds of gametogenesis in the SSD lines. A more

Table 1 Analyses of variance on the nine variates scored on the TT2 cross

\begin{tabular}{|c|c|c|c|c|c|c|c|c|c|c|}
\hline & $\mathrm{df}$ & $\begin{array}{l}\mathrm{Ht} \\
\text { M.S. }\end{array}$ & $\begin{array}{l}\text { TGW } \\
\text { M.S. }\end{array}$ & $\begin{array}{l}\text { MSW } \\
\text { M.S. }\end{array}$ & $\begin{array}{l}\text { EL } \\
\text { M.S. }\end{array}$ & $\begin{array}{l}\text { TN } \\
\text { M.S. }\end{array}$ & $\begin{array}{l}\text { GN } \\
\text { M.S. }\end{array}$ & $\begin{array}{l}\text { Mat } \\
\text { M.S. }\end{array}$ & $\begin{array}{l}\text { AE: } \\
\text { M.S. }\end{array}$ & $\begin{array}{l}\text { SPY } \\
\text { M.S. }\end{array}$ \\
\hline 1. Bet. Reps & 1 & $225 \cdot 90^{*}$ & $39 \cdot 47$ & $668 \cdot 00$ & $8 \cdot 05$ & $3 \cdot 09$ & $4 \cdot 48$ & $16 \cdot 06^{*}$ & $20 \cdot 51$ & $48 \cdot 19$ \\
\hline 2. Det. I)H & 19 & $139 \cdot 06^{*}$ & $31 \cdot 06$ & $1040 \cdot 00$ & $5.55^{*}$ & $18 \cdot 45$ & $29 \cdot 69^{*}$ & $5 \cdot 86$ & $14 \cdot 103$ & $22 \cdot 50$ \\
\hline $\begin{array}{l}\text { a. denso v mutans } \\
\text { b. Bet. lines }\end{array}$ & 1 & $1067 \cdot 87 \%$ & $5 \cdot 46$ & $397 \cdot 00$ & $65 \cdot 624$ & $39 \cdot 53$ & $0 \cdot 80$ & $4 \cdot 09$ & 0.00 & $122 \cdot 04^{*}$ \\
\hline within groups & 18 & $87 \cdot 46$ & $32 \cdot 48$ & $1075 \cdot 72$ & $2 \cdot 21$ & $17 \cdot 28$ & $31 \cdot 30$ & $5 \cdot 96$ & $24 \cdot 81$ & 16.97 \\
\hline 3. Bet. SSD & $37(2) \S$ & $106 \cdot 00 \div$ & $39 \cdot 70$ & $648 \cdot 88$ & $1 \cdot 94$ & $17 \cdot 01$ & $12 \cdot 11$ & $8 \cdot 30^{*}$ & 18.95 & $22 \cdot 98$ \\
\hline $\begin{array}{l}\text { a. denso v nutans } \\
\text { b. Bet. lines }\end{array}$ & 1 & $1025.95 \%$ & $113 \cdot 70$ & $1689 \cdot 70$ & $3 \cdot 56$ & $35 \cdot 06$ & $66 \cdot 34^{*}$ & $9 \cdot 37$ & $253 \cdot 43 \%$ & $44 \cdot 25$ \\
\hline within groups & $36(2) \S$ & $86 \cdot 34$ & $37 \cdot 64$ & 619.96 & $2 \cdot(k)$ & $17 \cdot 45$ & $11 \cdot 27$ & $8 \cdot 7.3$ & $13 \cdot 49$ & $22 \cdot 18$ \\
\hline 4. Within lines & $48(12) \S$ & $49 \cdot 25$ & $41 \cdot 33$ & $859 \cdot 03$ & $2 \cdot 61$ & $13 \cdot 05$ & $15 \cdot 41$ & $4 \cdot 43$ & $12 \cdot 87$ & $15 \cdot 65$ \\
\hline
\end{tabular}

* $\mathrm{P}<0.05,+\mathrm{P}<0.01,+\mathrm{P}<0 \cdot 0(0)$.

$\S$ Indicates number of missing plots. 
striking example is provided in the case of ear length. In the DH population all the additive genetic variation was associated with the denso gene, but following rounds of gametogenesis the contribution of alleles at this locus to $D$ totally disappeared. Snape and Simpson (1981) using DH lines developed by the $H$. bulbosum system also noted undesirable effects on agronomic characters associated with the denso gene. These authors, however, concluded that these effects were due to pleiotropy. By including the SSD lines it has been clearly shown that the associations, observed in this experiment, with the denso gene were due to linkage disequilibrium.

The analyses of variance for the Clipper $\times$ Ymer cross are given in table 3 . There was significant additive genetic variation for all nine variates scored. The means of the DH sub-populations ( 7 early: 13 late) differed for height, main stem weight, ear length, grain number and awn emergence. The means of the SSD sub-populations (12 early: 27 late) differed for awn emergence and maturity. Estimates of the portion of $(D)$ associated with the daylength response locus are presented in table 4 . The contribution of the daylength response locus to quantitative variation in the $\mathrm{DH}$ population ranges from 100 per cent (awn emergence) to $0 \cdot 0$ per cent for thousand grain weight.
The most striking feature of these data however, was the reduction in the contribution of the daylength response locus to quantitative variation following rounds of recombination. With the exception of maturity and awn emergence, as noted above, the daylength response locus did not contribute to quantitative variation in the SSD population. These data demonstrate very clearly that the association between the daylength response locus and quantitative variation was due to linkage disequilibrium rather than pleiotropy

\section{DISCUSSION}

The objectives of this investigation were to show the need for examining the effects of major gene loci on characters of agronomic importance. Clearly the denso and daylength response loci are associated with quantitative, agronomic characters. By comparing the contributions of individual loci to the additive genetic variance in the $\mathrm{DH}$ and SSD populations it has been demonstrated that in these cases the associations are due to linkage disequilibria. The means and ranges for the parents, DH and SSD lines for the TT5 cross are given in table 5 where awn emergence is omitted as it was used to classify the sub-populations. By

Table 3 Analyses of variance of the nine variates scored on the TT5 cross

\begin{tabular}{|c|c|c|c|c|c|c|c|c|c|c|}
\hline TT5 $($ Clipper $\times$ Ymer $)$ & $\mathrm{df}$ & $\begin{array}{l}\text { Ht } \\
\text { M.S. }\end{array}$ & $\begin{array}{l}\text { TGW } \\
\text { M.S. }\end{array}$ & $\begin{array}{l}\text { MSW } \\
\text { M.S. }\end{array}$ & $\begin{array}{l}\text { EL } \\
\text { M.S. }\end{array}$ & $\begin{array}{l}\text { TN } \\
\text { M.S. }\end{array}$ & $\begin{array}{l}\text { GN } \\
\text { M.S. }\end{array}$ & $\begin{array}{l}\text { Mat } \\
\text { M.S. }\end{array}$ & $\begin{array}{l}\text { AE } \\
\text { M.S. }\end{array}$ & $\begin{array}{l}\text { SPY } \\
\text { M.S. }\end{array}$ \\
\hline 1. Bet. reps. & 1 & $100 \cdot 45$ & $6 \cdot 28$ & $637 \cdot 30$ & $14 \cdot 12 \dagger$ & 1.72 & $2 \cdot 36$ & $6 \cdot 79$ & $80 \cdot 34^{*}$ & $51 \cdot 17$ \\
\hline \multirow[t]{3}{*}{ 2. Bet. DH } & $18(1) \S$ & $132 \cdot 80 \dagger$ & $69 \cdot 25^{*}$ & $1,962 \cdot 30 \div$ & $7 \cdot 83$ 本 & $11 \cdot 41$ & $49 \cdot 37 \dagger$ & $4 \cdot 64$ & $65 \cdot 27 \div$ & $25 \cdot 11$ \\
\hline & 1 & $572 \cdot 12 \dagger$ & $0 \cdot 00$ & $14,781 \cdot 6 \div$ & $76 \cdot 84 t$ & $30 \cdot 12$ & $505 \cdot 92 \ddagger$ & $0 \cdot 40$ & $1015 \cdot 28 \ddagger$ & $13 \cdot 79$ \\
\hline & $17(1) \S$ & 106.96 & $79 \cdot 92$ & $1,208 \cdot 22$ & $3 \cdot 77$ & $10 \cdot 31$ & $22 \cdot 51$ & 4.89 & $9 \cdot 39$ & $100 \cdot 33$ \\
\hline \multirow{3}{*}{$\begin{array}{l}\text { 3. Bet. SSD } \\
\text { a. "early" v "late" } \\
\text { b. Bet. lines } \\
\text { within groups }\end{array}$} & $38(1) \S$ & $145 \cdot 13 \div$ & $127 \cdot 58 \div$ & $2,900 \cdot 00 \div$ & $6 \cdot 95$ 末 & $24 \cdot 81+$ & $59 \cdot 83 \neq$ & $10 \cdot 07 \ddagger$ & $77 \cdot 96 \div$ & $43 \cdot 05$ 市 \\
\hline & 1 & $19 \cdot 56$ & $91 \cdot 04$ & $234 \cdot 30$ & $0 \cdot 15$ & $40 \cdot 85$ & $2 \cdot 06$ & $51 \cdot 61 \ddagger$ & $1723 \cdot 48 \ddagger$ & $3 \cdot 21$ \\
\hline & $37(1) \S$ & $148 \cdot 52$ & $128 \cdot 57$ & $2,972 \cdot 05$ & $7 \cdot 13$ & $24 \cdot 37$ & $61 \cdot 39$ & 8.95 & 33.49 & $44 \cdot 13$ \\
\hline 4. Within lines & $44(16) \S$ & $46 \cdot 94$ & $39 \cdot 46$ & $621 \cdot 18$ & $1 \cdot 44$ & $11 \cdot 08$ & $15 \cdot 68$ & $3 \cdot 16$ & $17 \cdot 88$ & $15 \cdot 48$ \\
\hline
\end{tabular}

$\S$ Indicates number of missing plots.

Table 4 Estimates of the portion of the additive genetic variation associated with the daylength response locus

\begin{tabular}{|c|c|c|c|c|c|c|c|c|c|}
\hline & $\mathrm{Ht}$ & TGW & MSW & EL & $\mathrm{TN}$ & GN & Mat & $\mathrm{AE}$ & SPY \\
\hline D. Haploids (Total D) & $42 \cdot 9$ & $14 \cdot 9$ & $670 \cdot 6$ & $3 \cdot 2$ & $0 \cdot 0$ & $16 \cdot 8$ & $0 \cdot 0$ & $25 \cdot 7$ & $0 \cdot 0$ \\
\hline "early"/"late" locus & $12 \cdot 9$ & $0 \cdot 0$ & $377 \cdot 0$ & $2 \cdot 0$ & $0 \cdot 0$ & $13 \cdot 4$ & 0.0 & $23 \cdot 7$ & 0.0 \\
\hline SSD Lines (Total $D$ ) & $43 \cdot 0$ & $38 \cdot 6$ & $997 \cdot 0$ & $2 \cdot 4$ & $6 \cdot 0$ & $19 \cdot 3$ & $3 \cdot 0$ & $26 \cdot 3$ & $12 \cdot 1$ \\
\hline "early"/"late" locus & 0.0 & 0.0 & 0.0 & $0 \cdot 0$ & $0 \cdot 0$ & $0 \cdot 0$ & 0.5 & $20 \cdot 8$ & $0 \cdot 0$ \\
\hline
\end{tabular}


Table 5 The means and ranges for the parents, $F_{1}$ doubled haploids and single seed descent lines from the TT5 cross

\begin{tabular}{|c|c|c|c|c|c|c|c|c|c|c|}
\hline & & & $\mathrm{Ht}$ & TGW & MSW & EL & TN & GN & Mat & SPY \\
\hline Parental & Clipper & & $48 \cdot 36$ & 56.71 & $86 \cdot 50$ & $6 \cdot 38$ & $9 \cdot 85$ & $16 \cdot 15$ & $2 \cdot 88$ & 6.98 \\
\hline Means & Ymer & & $59 \cdot 19$ & $53 \cdot 76$ & $168 \cdot 28$ & $12 \cdot 12$ & $9 \cdot 31$ & $31 \cdot 22$ & $4 \cdot 30$ & $11 \cdot 24$ \\
\hline \multirow{6}{*}{$\begin{array}{l}\text { Doubled } \\
\text { Haploids }\end{array}$} & & Meian & $51 \cdot 12$ & $55 \cdot 10$ & $106 \cdot 10$ & $7 \cdot 31$ & $11 \cdot 20$ & $19 \cdot 62$ & $3 \cdot 21$ & 8.92 \\
\hline & "carly" & Min & $47 \cdot 50$ & $39 \cdot 30$ & $81 \cdot 90$ & $6 \cdot 70$ & $6 \cdot 60$ & $17 \cdot 75$ & 1.50 & 4.95 \\
\hline & & Max & $59 \cdot 40$ & $62 \cdot 40$ & $140 \cdot 40$ & $8 \cdot 65$ & $14 \cdot 00$ & $25 \cdot 00$ & 6.50 & $13 \cdot 25$ \\
\hline & & Mean & $59 \cdot 40$ & $53 \cdot 10$ & $146 \cdot 50$ & $9 \cdot 93$ & $9 \cdot 26$ & $27 \cdot 15$ & $3 \cdot 83$ & $10 \cdot 25$ \\
\hline & "late" & Min & $41 \cdot 00$ & $4 ! \cdot 15$ & $95 \cdot 00$ & $7 \cdot 15$ & $6 \cdot 40$ & $22 \cdot 70$ & $2 \cdot(1) 0$ & $5 \cdot 90$ \\
\hline & & $\operatorname{Max}$ & $67 \cdot 20$ & $60 \cdot 55$ & $175 \cdot 80$ & $11 \cdot 65$ & $11 \cdot 00$ & $30 \cdot 90$ & $5 \cdot 00$ & $15 \cdot 75$ \\
\hline \multirow{7}{*}{ SSD } & & Mean & $55 \cdot 30$ & $53 \cdot 66$ & $122 \cdot 90$ & $8 \cdot 51$ & $10 \cdot 47$ & $22 \cdot 85$ & $2 \cdot 78$ & $9 \cdot 21$ \\
\hline & "carly" & Min & $48 \cdot 20$ & $44 \cdot 16$ & $98 \cdot 40$ & $7 \cdot 50$ & $6 \cdot 70$ & $18 \cdot 39$ & 0.95 & $4 \cdot 55$ \\
\hline & & $\operatorname{Max}$ & $62 \cdot 20$ & $56 \cdot 56$ & $149 \cdot 00$ & $10 \cdot 40$ & 14.65 & $28 \cdot 50$ & 5.00 & 13.55 \\
\hline & & & & & & & & & & \\
\hline & & Mean & $55 \cdot 20$ & $51 \cdot 22$ & $125 \cdot 00$ & $9 \cdot 04$ & $9 \cdot 00$ & $23 \cdot 47$ & $4 \cdot 42$ & $8 \cdot 80$ \\
\hline & "late" & Min & $37 \cdot 40$ & $27 \cdot 74$ & 62.90 & $4 \cdot 22$ & $5 \cdot 70$ & $14 \cdot 25$ & $1 \cdot 15$ & 4.90 \\
\hline & & $\operatorname{Max}$ & $73 \cdot 10$ & $67 \cdot 34$ & $181 \cdot 20$ & $13 \cdot 25$ & $10 \cdot 28$ & $31 \cdot 50$ & $7 \cdot 00$ & 13.49 \\
\hline
\end{tabular}

generating random inbred lines and classifying the lines for alleles at any one locus it is possible to produce inbreds which exceed the higher or lower scoring parent. In the early stages of of a breeding programme selection is largely visual and it has been considered both effective and efficient to fix simply inherited characters in the $F_{2}$ generation. The evidence presented here for the two genes studied clearly indicates that this approach is inadvisable. In this paper and that dealing with the GP ert locus (Powell, Thomas, Caligari and Jinks, 1985) two of the possible situations explaining the association between major genes and quantitatively varying characters have been demonstrated, i.e. tight linkage/pleiotropy and linkage which is broken down following three rounds of gametogenesis. Both these mechanisms are relatively easily dealt with in a breeding programme. In the case of very tight linkage or pleiotropy, random inbred lines produced by SSD or DH from $F_{1}$ hybrids will be equally effective. Where linkdisequilibrium is implicated, rounds of gametogenesis should be encouraged to allow undesirable linkages to be broken down and hence SSD would be a suitable strategy. Alternatively $\mathrm{DH}$ could be produced from $\mathrm{F}_{3}$ or later generations. Other relationships could theoretically exist e.g. a desirable allele at a major gene locus linked to desirable quantitative character expression, in this case $\mathrm{DH}$ produced from $\mathrm{F}_{1}$ hybrids would clearly prove to be advantageous. Many other relationships could be envisaged but the methods described in this paper, which are not confounded with background effects, allows the breeder to examine the relationships between major genes and agronomic characters and then adopt the most suitable strategy for the deployment of major genes.

Acknowledgements We gratefully acknowledge the technical assistance of $\mathrm{Mr} \mathrm{G}$. R. Drabble and Mr W. Wood. We are also grateful to $\mathrm{Mr} \mathrm{M}$. S. Phillips for his help with some aspects of the computing. The advice and encouragement of Dr A. M. Hayter during the early stages of this work is gratefully acknowledged.

\section{REFERENCES}

AL-BANNA, M. K. S., IINKS, J. I. AND POONI, H. S. 1984. The contribution of pleiotropy at the mop loci to continuous variation in Nicotiana rustica. Heredity, 52, 95-102.

IIAAR, V. ANI) VON WI:ITSTRIIN, I). 1975. Studies of an induced high yiclding dwarf-mutant of spring barley. In Proc. 3 rd Int. Barley Genet. Symp., Garching, pp. 215-218.

POWELL, W. THOMAS, W. 'T. B., (AI.KIARI, P. I). S. AND JINKS, J. 1. 1985. The effects of major genes on quantitatively varying characters in barley. 1 . The GP ert locus. Heredity, $54,34.3-348$.

SNAPE, J. W. ANI SIMPSON, 1: 1981. The use of doubled haploids for genetical analysis in barley. In Proc. 4th Int. Barley Genet. Symp., Edinburgh. Edinburgh Univ. Press. pp. 704-709.

THOMSON, W. I. AND MATTHEWS, S. 1981. The effect of daylength and sowing date on ear development in barley cultivars. In Proc. 4th Int. Barley (jenet. Symp., Edinburgh. Edinburgh Univ. Press, pp. 518-526. 